\title{
Job strain: a cross-sectional survey of dementia care specialists and other staff in Swedish home care services
}

This article was published in the following Dove Press journal: Journal of Multidisciplinary Healthcare

\author{
Linda Sandberg' \\ Lena Borell' \\ David Edvardsson ${ }^{2,3}$ \\ Lena Rosenberg' \\ Anne-Marie Boström ${ }^{1,4,5}$ \\ 'Department of Neurobiology, Care \\ Sciences and Society (NVS), Division \\ of Occupational Therapy, Karolinska \\ Institutet, Huddinge, Sweden; ${ }^{2}$ School \\ of Nursing and Midwifery, La Trobe \\ University, Heidelberg, VIC, Australia; \\ ${ }^{3}$ Department of Nursing, Umea \\ University, Umea, Sweden; ${ }^{4}$ Theme \\ Aging, Karolinska University Hospital, \\ Stockholm, Sweden; ${ }^{5}$ Department of \\ Nursing, Western Norway University \\ of Applied Sciences, Haugesund, \\ Norway
}

Introduction: An increasing number of older persons worldwide live at home with various functional limitations such as dementia. So, home care staff meet older persons with extensive, complex needs. The staff's well-being is crucial because it can affect the quality of their work, although literature on job strain among home care staff is limited.

Aim: To describe perceived job strain among home care staff and to examine correlations between job strain, personal factors, and organizational factors.

Methods: The study applied a cross-sectional survey design. Participants were dementia care specialists who work in home care $(n=34)$ and other home care staff who are not specialized in dementia care $(n=35)$. The Strain in Dementia Care Scale (SDCS) and Creative Climate Questionnaire instruments and demographic variables were used. Descriptive and inferential statistics (including regression modeling) were applied. The regional ethical review board approved the study.

Results: Home care staff perceived job strain - particularly because they could not provide what they perceived to be necessary care. Dementia care specialists ranked job strain higher $(\mathrm{m}=5.71)$ than other staff members $(\mathrm{m}=4.71 ; p=0.04)$. Job strain (for total score and for all five SDCS factors) correlated with being a dementia care specialist. Correlations also occurred between job strain for SDCS factor 2 (difficulties understanding and interpreting) and not having Swedish as first language and SDCS factor 5 (lack of recognition) and stagnated organizational climate.

Conclusion: The study indicates that home care staff and particularly dementia care specialists perceived high job strain. Future studies are needed to confirm or reject findings from this study. Keywords: aging-in-place, home care services, work situation, language, organization, stress

\section{Introduction}

The population is aging worldwide. ${ }^{1}$ As the population ages, the number of individuals with dementia or cognitive impairment and other functional limitations will rise. Currently, 47 million persons worldwide live with dementia; by 2050, this number is expected to increase to $>121$ million. ${ }^{2}$ Going forward, associated care costs for older persons with dementia will represent a large portion of costs for society. ${ }^{3}$ The implications might be that more will be required of health care systems with fewer resources. ${ }^{4}$ In Sweden and many other countries, the current aging-in-place policy implies that individuals stay in their homes even if they have a dementia diagnosis. ${ }^{5}$ Institutional care beds (as in residential care) decreased, while the number of persons living at home (with home care service) increased due to this care approach for older persons in Sweden. Home care services increased from 7.9\% to 8.9\% (from 2001 to 2012,
Correspondence: Linda Sandberg Department of Neurobiology, Care Sciences and Society (NVS), Division of Occupational Therapy, Karolinska Institutet, Fack 23 200, SE-14I 83 Huddinge, Sweden Email linda.m.sandberg@ki.se 
among persons aged $>65$ years), but this does not fully compensate for the decrease in institutional care for older persons (from $7.7 \%$ in 2001 to $4.9 \%$ in 2012). ${ }^{6}$

Organization of home care varies among countries and may vary within a country, which is the case in Sweden. ${ }^{7}$ In Sweden, tax revenue constitutes the main source of home care funding that is earmarked for providing services to all citizens. ${ }^{8}$ Internationally, the workforce of home care providers comes under a variety of names including, for example, staff support worker or home care provider. ${ }^{4}$ This article calls these persons home care staff. As per Sweden's Social Services Act, home care staff should support older persons' day-to-day existence in cases in which their needs cannot otherwise be met. ${ }^{9}$ Municipal assessors evaluate the need for home care support that covers, for example, meal preparation, cleaning, laundry, and personal care. ${ }^{10}$ Emotional and social support can also be provided. ${ }^{11}$

Because older persons often have functional limitations (e.g., dementia), home care services evolved to become increasingly more advanced, thus requiring more knowledge and skills among staff members. ${ }^{12}$ Registered nurses, for example, can delegate tasks to home care staff (e.g., more advanced tasks such as treating wounds, administering prescribed medications). ${ }^{13}$ Home care staff often work alone in the older persons' home. ${ }^{14}$ This implies that they must rely on their own skills and abilities to provide care ${ }^{15}$ Home care staff members are not always trained to care for persons with extensive functional limitations such as dementia. To support dementia care staff, Sweden's National Board of Health and Welfare developed national guidelines for providing appropriate care for persons with dementia. ${ }^{16}$ These guidelines emphasize evidence-based interventions and advocate a person-centered approach. They also recommend that staff members have dementia care education, regular guidance, and allocated time for reflection on their work..$^{16,17}$

Previous residential care research reveals that a perceived high level of well-being among staff is associated with provision of high-quality care. ${ }^{18}$ Staff well-being is crucial for staff members and for those who receive care. One of the most important factors for work satisfaction is to have the experience of providing person-centered care. ${ }^{19}$ But not being able to provide appropriate, necessary care is a major source of job strain..$^{20}$ Risk for misunderstandings and nursing care failures increases for nursing staff members who experience stress and shortcomings. ${ }^{18,21}$ Other studies disclosed that nursing home employees report increased stress due to residents' psychological and behavioral problems. ${ }^{18,22}$
According to Knapp, ${ }^{23}$ stress and strain are interrelated concepts because job strain can be the effect of stress in a work situation. A study that focused on investigating strain among nurse assistants in residential care found that job strain is associated with personal factors (e.g., age and education) and organizational factors (e.g., leadership and organizational and environmental support). ${ }^{24}$ In home care, organizational support from supervisors and managers is required to reinforce employees' well-being. ${ }^{25}$

As populations age, many countries face the associated problems of caring for older persons living at home with dementia and other functional limitations. So, work situations for home care staff dramatically changed in recent years. ${ }^{25,26}$ But the literature on how home care staff perceive job strain when supporting older persons is limited. Understanding job strain is crucial because residential care research revealed that staff members' well-being affects care quality for residents. To increase this knowledge, this study described the perceived job strain among home care staff and examined correlations between job strain, personal factors, and organizational factors. These research questions were investigated:

- To what degree do home care staff members perceive job strain?

- Are there differences among home care staff when they rate job strain (i.e., do dementia care specialists rate job strain differently compared with other staff)?

- Are there correlations between job strain ratings and other factors (personal and organizational factors)?

\section{Methods Design}

The study applied a cross-sectional survey design.

\section{Setting and sample}

The study was conducted in a city in Sweden. One home care agency was invited to participate. Participants were recruited from the agency, which had five units in varying geographic areas. The agency had about 400 employees who served for about 1000 persons, of whom $20-30 \%$ were estimated to have cognitive impairment and/or dementia. Services were provided 24/7. Each agency unit had specialized staff (called dementia care specialists in this article). As per the aforementioned guidelines for persons with dementia, ${ }^{16}$ dementia care specialists should have dementia care education (at this agency, a web-based course was recommended), and these staff members were allocated 1 hour each week 
for reflection and guidance regarding caring for persons with dementia. Other staff working for the agency had no pronounced specific specialization and no expectations of being trained to care for persons with dementia (called other staff).

All staff members provided care to persons with varying types of functional limitations. Compared with other staff, dementia care specialists worked more extensively with persons who had a dementia diagnosis and particularly with persons who had increased special needs. The inclusion criterion in this study was that the participants had to provide care and services for older persons; the exclusion criterion was working only night shifts.

\section{Ethical approval}

The regional ethical review board in Stockholm, Sweden (registration numbers 2014/1014-31/4, 2014/1894-32), approved the study.

\section{Instruments}

The Strain in Dementia Care Scale (SDCS) ${ }^{20}$ and Creative Climate Questionnaire (CCQ) ${ }^{27}$ were selected because they assess the area of interest for this study, that is, job strain and organizational climate. These instruments were developed, validated, and used in similar contexts in Sweden; permission to use them was obtained.

Job strain was measured with a slightly revised version of the SDCS. ${ }^{20}$ The revisions were made because the instrument was originally designed for staff working with persons with dementia in institutional care. The instructions in the survey were rephrased to address caring for persons with dementia and other functional limitations. The term residents/clients was replaced with older persons because they still lived in their homes. The SDCS consists of 27 statements. A respondent rates each statement. Taken together, a respondent's ratings generate a total score, which covers the following five factors:

Factor 1: frustrated empathy (seven statements)

Factor 2: difficulties understanding and interpreting (seven statements)

Factor 3: balancing competing needs (five statements)

Factor 4: balancing emotional involvement (four statements)

Factor 5: lack of recognition (four statements)

Two, four-point response scales appear at the end of each statement (how often the situation occurs and level of stress it causes when it occurs). Regarding frequency, response options range from $1=$ never to $4=$ very often. Stress level options range from $1=$ none to $4=$ high. Upon calcula- tion, response options are multiplied for each statement (range 1-16). A high score indicates a high level of job strain. Currently, no cutoff scores exist within this instrument for describing various job strain levels. A previous study reported mean values between 2.7 and 3.7. ${ }^{24}$

Two previous studies and the present study report these Cronbach's alpha values for SDCS:

- Total score $=0.91,{ }^{24} 0.92,{ }^{28}$ and 0.92 (present study)

- Five factors=between 0.65 and $0.82,{ }^{24}$ between 0.66 and $0.77,{ }^{28}$ and between 0.53 and 0.90 (present study).

Organizational factors were measured using the $\mathrm{CCQ} \cdot{ }^{27}$ The CCQ was used in several Swedish studies. ${ }^{19,24,29,30}$ The CCQ consists of 50 statements, which, taken together, generate a total score and these 10 dimensions (five statements per dimension):

- Challenge: Emotional involvement of members in the operations and goals of the organization

- Freedom: Independence in behavior demonstrated by organization members

- Idea support: Manner in which new ideas are received

- Trust/openness: Degree of trust that is conveyed and experienced in the relationship

- Dynamism/liveliness: Eventfulness and dynamics of the organization

- Playfulness/humor: Display of an informal, spontaneous, relaxed atmosphere

- Debate: Occurrence of encounters and clashes concerning differences of opinions, ideas, experiences, and knowledge

- Conflicts: Presence of interpersonal conflicts and emotional tension (in contrast to conflicts between ideas) in the organization

- Risk taking: Ability to tolerate uncertainty in the organization

- Ideas time: Time individuals can use for introduction or suggestion of new ideas

Response options for the statements are on a four-point scale that ranges from $0=$ not at all to $3=$ to a high degree. High scores indicate a creative organizational climate except for the conflicts dimension; here, high scores indicate stagnated organizational climate.

One previous study ${ }^{24}$ and the present study report these Cronbach's alpha values for CCQ:

- Total score $=0.79^{24}$ and 0.93 (present study)

- Ten dimensions=between 0.62 and $0.88^{24}$ and between 0.55 and 0.86 (present study). 


\section{Data collection}

In 2014, data collection occurred in two phases at the agency.

In Phase I, dementia care specialists in home care $(n=34)$ were invited to participate in the study, and surveys were distributed at a meeting. The researchers were present to answer questions when needed.

In Phase II, other home care staff members $(\mathrm{n}=35)$ were invited to participate, and surveys were distributed within the agency's units; distribution ended when the number of respondents was comparable with the number of respondents in the first data collection phase.

All participants received written and oral information, which specified that participation was voluntary and anonymous. If a participant chose to answer the survey questions, it was accepted as written informed consent to participate in the study.

The survey included the SDCS and CCQ, and additional questions for collecting participant characteristics, namely gender, age, educational level (high school and university course), dementia care education (yes/no), Swedish as first language (yes/no), employment (permanent/temporary), years of employment, how long they had cared for persons with dementia, and working hours (day shifts and day shifts including weekends and evenings).

\section{Data analysis}

The Statistical Package of the Social Sciences version 22 was used. ${ }^{31}$

\section{Imputation}

Missing SDCS and CCQ values were dealt with before analyses were run. When $\leq 50 \%$ of the values for each factor or dimension was missing, a mean was calculated - based on the reported values for each respondent. The calculated mean replaced the missing value. ${ }^{32}$

\section{Consistency}

Before summarizing scores and calculating the mean of values assigned to the five SDCS factors, the two response scales for frequencies and stress level were multiplied for each of the 27 statements. To make the scales consistent for calculating the total CCQ score, where a high score indicated creative organizational climate, response option values for the conflict dimension were reversed. The score for each CCQ dimension is the calculated mean of statements within the dimension. Cronbach's alpha was used to test for the instruments' internal consistency.

\section{Analyses}

Descriptive analyses were done to describe frequencies and distributions. The total SDCS score and the five SDCS factors were used to measure job strain (dependent variables). Due to the small sample size, not all independent variables could be included in the regression models.

Independent variables were classified as personal factors: gender, age, educational level, dementia care education, Swedish as first language, years of employment, length of time working with persons with dementia, and working hours. The 10 dimensions and the total CCQ score constituted organizational factors. The analysis for examining the correlations between job strain (dependent variable) and personal factors and organizational factors (independent variables) was carried out in three phases.

In Phase I, bivariate analysis was conducted using dependent and independent variables. Student's $t$-test measured differences between the dependent variable (SDCS) and the independent variables regarding personal factors. Pearson's correlation coefficient measured correlations between the SDCS and CCQ scores and continuous variables (e.g., age). Independent variables that were statistically significant $(p \leq 0.05)$ from the bivariate analyses were included in Phase II.

In Phase II, multicollinearity between the independent variables from the previous analyses was checked using Spearman's rank correlation coefficient; here, a $p$-value $>0.85$ indicated whether a covarying variable should be excluded. ${ }^{32}$

In Phase III, multiple linear regression models were used with independent variables from Phase II. The dementia care education variable was also included in the regression models.

A $p$-value $\leq 0.05$ was considered to indicate a statistically significant difference or correlations.

\section{Results}

\section{Home care staff characteristics}

This study included 69 home care services employees; the home care staff characteristics are presented in Table 1. Thirty-four $(49 \%)$ persons were dementia care specialists, and 35 (51\%) were not specialized. The majority were women. Ages ranged between 21 and 64 years; mean age was 46.3. Thirty-eight (55\%) persons had Swedish as their first language. Length of home care employment ranged between 1 and 40 years $(\mathrm{m}=14.7)$.

Two significant differences were found when comparing dementia care specialists with other staff members:

- $79 \%(n=27)$ of dementia care specialists had dementia care education compared with other staff $(34 \% ; n=12)$ who had no dementia care education $(p<0.01)$. 
Table I Characteristics of home care staff for the total sample, dementia care specialists, and other staff

\begin{tabular}{|c|c|c|c|c|}
\hline Variables & Total sample & $\begin{array}{l}\text { Dementia care } \\
\text { specialists }\end{array}$ & Other staff & $p$-value \\
\hline Number & 69 & 34 & 35 & \\
\hline Gender, n (\%) & & & & 0.499 \\
\hline Female & $56(8 I)$ & $29(85)$ & $27(77)$ & \\
\hline Male & $12(19)$ & $5(15)$ & $7(23)$ & \\
\hline Age, mean (SD) & & & & 0.272 \\
\hline Years & $46.3(11.5)$ & $47.9(9.9)$ & $44.8(12.8)$ & \\
\hline \multicolumn{5}{|l|}{ Education, n (\%) } \\
\hline High school & $58(85)$ & $29(88)$ & $29(83)$ & 0.559 \\
\hline University course & $20(29)$ & II (55) & $9(45)$ & 0.491 \\
\hline Dementia care education & $39(57)$ & $27(79)$ & $12(34)$ & $<0.01$ \\
\hline \multicolumn{5}{|l|}{ Language, n (\%) } \\
\hline Swedish as first language: yes & $38(55)$ & $17(50)$ & $21(60)$ & 0.404 \\
\hline \multicolumn{5}{|l|}{ Length of employment (years), mean (SD) } \\
\hline Length of employment in home care service & I4.7 (10.7) & $14.7(10.3)$ & | 4.7 (| I.2) & 0.976 \\
\hline $\begin{array}{l}\text { Length of time working with persons with dementia in home care or } \\
\text { in institutional care }\end{array}$ & I5.2(10.6) & $14.8(10.7)$ & $15.5(10.7)$ & 0.777 \\
\hline Employment, n (\%) & & & & 1.00 \\
\hline Permanent & $64(94)$ & $32(94)$ & $32(94)$ & \\
\hline Working hours, n (\%) & & & & 0.009 \\
\hline Daytime - weekdays & $42(61)$ & $15(44)$ & $27(77)$ & \\
\hline Daytime - weekends & $15(22)$ & $9(27)$ & $6(17)$ & \\
\hline Evenings & $12(17)$ & $10(29)$ & $2(6)$ & \\
\hline
\end{tabular}

Note: Significant values are shown in bold $(\leq 0.05)$.

- A higher percentage of dementia care specialists $(29 \%$; $\mathrm{n}=10)$ worked evenings compared with other staff $(6 \%$; $\mathrm{n}=2 ; p<0.01)$.

\section{Job strain among home care staff}

Tables 2 and $\mathrm{S} 1$ display job strain ratings. For the total sample, the mean score for job strain was 5.22. The range between the highest and lowest mean score for the five factors were 5.95 (factor 3: balancing competing needs) and 4.43 (factor 2: difficulties understanding and interpreting). For the 27 SDCS statements, the mean score varied between 7.50 and 3.11. The three statements with the highest mean scores were as follows:

- I want to do much more for the older persons than my employers will allow $(\mathrm{m}=7.50)$.

- Older persons do not receive the care I feel they are entitled to $(\mathrm{m}=7.48)$.

- I feel that older persons are highly dependent on me $(\mathrm{m}=7.33)$.

\section{Job strain comparison between dementia care specialists and other staff}

Dementia care specialists rated the total score for job strain $(\mathrm{m}=5.70)$ higher than other staff $(\mathrm{m}=4.71 ; p=0.04)$ (Table 2$)$. Specialists had significant higher mean job strain values for three factors $(1,3$, and 5$)$ compared with other staff. Findings from these factors indicate more frustration, more difficulty in balancing needs, and less recognition for dementia care specialists.

On the statement level, dementia care specialists had significantly higher scores regarding job strain in six of the 27 statements:

- I see other staff behaving toward an older person in a way that shows they do not understand the effects of dementia $(\mathrm{m}=8.22$ vs. $\mathrm{m}=5.16 ; p<0.01)$.

- I see other staff treating the older persons badly $(\mathrm{m}=3.72$ vs. $\mathrm{m}=2.50 ; p=0.05)$.

- I must balance the needs of the older person against the needs of his or her family $(\mathrm{m}=7.42$ vs. $\mathrm{m}=4.97 ; p=0.01)$.

- I must balance the needs of the older person against the needs of other older persons $(\mathrm{m}=7.29$ vs. $\mathrm{m}=4.40 ; p=0.01)$.

- I cannot stop thinking about older persons when I am away from work ( $\mathrm{m}=4.58$ vs. $\mathrm{m}=2.97$; $p=0.04)$.

- I feel that others do not value my work ( $\mathrm{m}=6.88$ vs. $\mathrm{m}=4.31 ; p=0.01$ ) (Table S1).

\section{Organizational climate among home care staff}

The mean score for total CCQ for the total sample was 1.59 , and the range for the 10 dimensions in the CCQ was between 1.92 for the challenge dimension and 1.03 for the ideas time dimension (Table S2). No significant differences 
were found between dementia care specialists and other staff regarding CCQ ratings (neither CCQ total score nor the 10 dimensions ratings).

\section{Correlations between perceived job strain among all staff and personal factors and organizational factors}

In the bivariate analyses (Phase I), one significant difference was found between SDCS factor 2 (difficulties understanding and interpreting) and Swedish as first language $(p<0.01)$ when comparing job strain (SDCS total score and SDCS factors for total sample) with personal factors. There were significant differences for all statements included in factor 2, all pointing in the same direction; that is, staff members who did not have Swedish as their first language had a higher job strain mean (Table 3).

Three correlations were found between job strain (SDCS) and organizational climate (CCQ), namely, SDCS factor 5 (lack of recognition) correlated with:

- The CCQ total $(r=-0.27 ; p=0.04)$

- Two CCQ dimensions: idea support ( $r=-0.37 ; p \leq 0.01)$ and conflicts $(r=0.27 ; p=0.04)$
These findings indicate that increased job strain - as per factor 5 (lack of recognition) - correlated with stagnated organizational climate and a lower rating on idea support and a higher rating on conflicts.

Four independent variables were used in the multiple linear regression models: dementia care specialization, Swedish as first language, dementia care education, and organizational climate (CCQ total score). These four variables were not covarying as per Phase II. The multiple linear regression model (Phase III) explained $15 \%$ of the variance of job strain (total score) among home care staff (Table 4). Job strain (total score) was correlated with dementia care specialists $(\beta=1.744, p=0.004)$. Regarding factor 2 , difficulties understanding and interpreting, the independent variables included in the multiple regression model explained 25.4\% of the variance. Two independent variables, Swedish as the first language $(\beta=1.981, p=0.001)$ and dementia care specialization $(\beta=1.229, p=0.047)$, were correlated with factor 2 (difficulties understanding and interpreting). For factor 5 (lack of recognition), the independent variables included in the multiple regression model explained $15.4 \%$ of the variance. Two independent variables, organizational climate $(\beta=-1.775, p=0.020)$ and dementia care specialization

Table 2 SDCS scores (total and factors) for the total sample, specialists, and other staff in home care service

\begin{tabular}{|c|c|c|c|c|c|c|c|c|}
\hline \multirow[t]{2}{*}{ SDCS } & \multicolumn{3}{|c|}{ Total sample } & \multicolumn{2}{|c|}{$\begin{array}{l}\text { Dementia care } \\
\text { specialists }\end{array}$} & \multicolumn{2}{|c|}{ Other staff } & \multirow[t]{2}{*}{$p$-value } \\
\hline & $\begin{array}{l}\text { Cronbach's } \\
\text { alpha }\end{array}$ & $\mathbf{N}$ & Mean (SD) & $\mathbf{N}$ & Mean (SD) & $\overline{\mathbf{N}}$ & Mean (SD) & \\
\hline Total strain & 0.92 & 57 & $5.22(1.86)$ & 29 & $5.70(2.18)$ & 28 & $4.71(1.32)$ & 0.04 \\
\hline Factor I: frustrated empathy & 0.85 & 64 & $5.41(2.38)$ & 32 & $6.15(2.63)$ & 32 & $4.67(1.86)$ & 0.01 \\
\hline Factor 2: difficulties understanding and interpreting & 0.90 & 64 & $4.43(2.13)$ & 33 & $4.76(2.30)$ & 31 & $4.07(1.91)$ & 0.20 \\
\hline Factor 3: balancing competing needs & 0.85 & 61 & $5.95(2.97)$ & 31 & $6.85(3.46)$ & 30 & $5.02(2.01)$ & 0.01 \\
\hline Factor 4: balancing emotional involvement & 0.75 & 63 & $5.18(2.5 \mathrm{I})$ & 30 & $5.68(2.79)$ & 33 & $4.72(2.17)$ & 0.14 \\
\hline Factor 5: lack of recognition & 0.53 & 63 & $5.90(2.37)$ & 32 & $6.59(2.59)$ & 31 & $5.19(1.92)$ & 0.02 \\
\hline
\end{tabular}

Notes: Possible range for SDCS 1-16. High scores indicate higher job strain. Significant values are shown in bold $(\leq 0.05)$.

Abbreviation: SDCS, Strain in Dementia Care Scale.

Table 3 Difficulties understanding and interpreting for staff with and without Swedish as their first language

\begin{tabular}{|c|c|c|c|c|c|}
\hline \multirow[t]{2}{*}{ SDCS } & \multicolumn{2}{|c|}{$\begin{array}{l}\text { Swedish as first } \\
\text { language }\end{array}$} & \multicolumn{2}{|c|}{$\begin{array}{l}\text { Not Swedish as } \\
\text { first language }\end{array}$} & \multirow[t]{2}{*}{$p$-value } \\
\hline & $\mathbf{N}$ & Mean (SD) & $\mathbf{N}$ & Mean (SD) & \\
\hline Factor 2: difficulties understanding and interpreting & 37 & $3.64(1.35)$ & 27 & $5.50(2.53)$ & $<0.01$ \\
\hline I have difficulties understanding what older persons are thinking & 38 & $4.34(2.06)$ & 28 & $5.93(3.32)$ & 0.03 \\
\hline I have difficulties understanding what older persons are trying to communicate & 37 & $3.81(1.54)$ & 28 & $5.54(3.13)$ & 0.01 \\
\hline I have difficulties understanding the needs of the older persons & 37 & $3.41(2.02)$ & 27 & $4.89(2.72)$ & 0.02 \\
\hline I find it difficult to know what is best for older persons & 37 & $3.22(1.73)$ & 27 & $5.78(3.56)$ & $<0.01$ \\
\hline I worry I might upset or hurt older persons because I do not understand their needs & 37 & $3.43(2.09)$ & 27 & $5.33(3.36)$ & 0.01 \\
\hline I cannot understand why older persons behave the way they do & 37 & $3.46(1.76)$ & 29 & $5.31(2.5 I)$ & $<0.01$ \\
\hline I have difficulties explaining to older persons what is happening & 38 & $3.79(2.4 I)$ & 30 & $5.57(3.93)$ & 0.04 \\
\hline
\end{tabular}

Notes: Possible range for SDCS I-16. High scores indicate higher job strain. Significant values are shown in bold $(\leq 0.05)$.

Abbreviation: SDCS, Strain in Dementia Care Scale. 
Table 4 SDCS scores (total and factors) correlated with personal factors and organizational factors

\begin{tabular}{|c|c|c|c|c|c|c|}
\hline $\begin{array}{l}\text { SDCS } \\
\text { Dependent variable }\end{array}$ & $\begin{array}{l}\text { Final model } \\
\text { Independent variables }\end{array}$ & $R_{\text {adj }}^{2}$ & $\boldsymbol{\beta}$ & B & $\begin{array}{l}95 \% \mathrm{Cl} \text { for } \\
\text { coefficient B }\end{array}$ & p-value \\
\hline \multirow[t]{5}{*}{ Total strain } & & 0.150 & & & & \\
\hline & Dementia care specialization: specialists $(\mathrm{I})$; other staff $(0)$ & & 1.744 & 0.459 & 0.585 to 2.904 & 0.004 \\
\hline & First language: not Swedish (I); Swedish (0) & & 0.571 & 0.143 & -0.500 to 1.642 & 0.289 \\
\hline & Dementia care education: no (I); yes $(0)$ & & 0.999 & 0.258 & -0.186 to 2.185 & 0.097 \\
\hline & Organizational climate (total CCQ score) & & -0.732 & -0.160 & -1.937 to 0.473 & 0.228 \\
\hline Factor I: frustrated & & 0.135 & & & & \\
\hline \multirow[t]{4}{*}{ empathy } & Dementia care specialization: specialists $(I)$; other staff $(0)$ & & 2.353 & 0.498 & 0.968 to 3.737 & 0.001 \\
\hline & First language: not Swedish (I); Swedish (0) & & 0.077 & 0.016 & -1.195 to 1.349 & 0.904 \\
\hline & Dementia care education: no $(\mathrm{I})$; yes $(0)$ & & 1.320 & 0.272 & -0.093 to 2.734 & 0.066 \\
\hline & Organizational climate (total CCQ score) & & -0.485 & -0.082 & -1.970 to 0.999 & 0.515 \\
\hline Factor 2: difficulties & & 0.254 & & & & \\
\hline understanding and & Dementia care specialization: specialists $(1)$; other staff $(0)$ & & 1.229 & 0.279 & 0.015 to 2.442 & 0.047 \\
\hline \multirow[t]{3}{*}{ interpreting } & First language: not Swedish (I); Swedish (0) & & 1.981 & 0.439 & $0.89 \mid$ to $3.07 \mid$ & 0.001 \\
\hline & Dementia care education: no ( 1 ); yes $(0)$ & & 0.741 & 0.165 & -0.498 to 1.979 & 0.236 \\
\hline & Organizational climate (total CCQ score) & & -0.354 & -0.067 & -1.592 to 0.884 & 0.568 \\
\hline Factor 3: balancing & & 0.099 & & & & \\
\hline \multirow[t]{4}{*}{ competing needs } & Dementia care specialization: specialists $(I)$; other staff $(0)$ & & 2.065 & 0.347 & 0.242 to 3.889 & 0.027 \\
\hline & First language: not Swedish (I); Swedish (0) & & 1.259 & 0.204 & -0.406 to 2.924 & 0.135 \\
\hline & Dementia care education: no $(\mathrm{I})$; yes $(0)$ & & 0.584 & 0.095 & $-\mid .274$ to $2.44 \mid$ & 0.531 \\
\hline & Organizational climate (total CCQ score) & & -0.181 & -0.025 & -2.102 to $1.74 \mid$ & 0.851 \\
\hline Factor 4: balancing & & 0.127 & & & & \\
\hline emotional & Dementia care specialization: specialists $(\mathrm{I})$; other staff $(0)$ & & 1.768 & 0.341 & $0.25 \mathrm{I}$ to 3.285 & 0.023 \\
\hline \multirow[t]{3}{*}{ involvement } & First language: not Swedish (I); Swedish (0) & & 1.057 & 0.197 & -0.365 to 2.479 & 0.142 \\
\hline & Dementia care education: no $(\mathrm{I})$; yes $(0)$ & & 1.393 & 0.266 & -0.171 to 2.956 & 0.080 \\
\hline & Organizational climate (total CCQ score) & & -1.093 & -0.171 & -2.727 to 0.540 & 0.185 \\
\hline Factor 5: lack of & & 0.154 & & & & \\
\hline \multirow[t]{4}{*}{ recognition } & Dementia care specialization: specialists $(I)$; other staff $(0)$ & & 1.921 & 0.391 & 0.500 to 3.342 & 0.009 \\
\hline & First language: not Swedish (I); Swedish (0) & & 0.343 & 0.067 & -0.968 to 1.654 & 0.602 \\
\hline & Dementia care education: no $(\mathrm{I})$; yes $(0)$ & & 0.460 & 0.091 & -0.996 to 1.916 & 0.529 \\
\hline & Organizational climate (total CCQ score) & & -1.775 & -0.298 & -3.262 to -0.288 & 0.020 \\
\hline
\end{tabular}

Note: Significant values are shown in bold $(\leq 0.05)$.

Abbreviations: SDCS, Strain in Dementia Care Scale; CCQ, Creative Climate Questionnaire.

$(\beta=1.921, p=0.009)$, were correlated with factor 5 (lack of recognition). The independent variables explained between $9.9 \%$ and $13.5 \%$ of the variance for the remaining factors (1, 3 , and 4 ). In these three regression models, dementia care specialization was the only independent variable that correlated significantly with these three factors $(1,3$, and 4$)$ (Table 4$)$.

\section{Discussion}

This is the first study to investigate job strain using the SDCS for home care staff. All respondents assigned high ratings to these survey statements: they wanted to do much more for the older persons than their employers would allow $(\mathrm{m}=7.50)$, and the older persons did not receive the care that they were entitled to $(m=7.48)$. This is aligned with findings from a previous study, which revealed that nursing staff, who care for persons with dementia in home care, day care, and institutional care, wanted to do much more than they actually could to decrease suffering and increase quality of life for persons with dementia. ${ }^{33}$ The findings in the present study show that staff in home care services manifested higher mean scores on job strain (total score $m=5.22$ ) compared with a study among staff working in residential care $(m=3.3) .{ }^{24}$ Mean scores for home care staff ratings of the five SDCS factors varied between 5.95 and 4.43, compared with 3.7-2.7 reported in another study. ${ }^{24}$ So therefore, the reported job strain scores in this study are interpreted to be high.

The work situation probably explains the home care staff's higher ratings on job strain, compared with staff working in residential care. Providing home care services implies that they work alone, ${ }^{14}$ and that home care staff must rely extensively on their own capacity and competence. ${ }^{15,26}$ Unmet care needs (as reported in the present study) appeared to be a consistent predictor of depression for home care workers in the US. ${ }^{34}$ Based on the worldwide trend that older persons with functional limitations live at home, home care staff will be caring for persons who have extensive, complex health 
care needs such as mental and behavioral health conditions and palliative care. ${ }^{25,26}$ This change resulted in new, increased demands on home care staff. ${ }^{12}$ Previous studies revealed that home care staff could be under physical and mental pressure in varying ways (e.g., musculoskeletal injury ${ }^{35}$ and violence).${ }^{15,35}$ Even if home care staff might be under pressure, they perceived high levels of job satisfaction largely due to close relationships that they develop with their clients, freedom to work independently, and job flexibility. ${ }^{35}$

In the present study, dementia care specialists in home care rated job strain significantly higher than other staff members. The regression analyses confirmed this finding; here, the independent variable (specialist staff) was significantly correlated with total score and all five SDCS factors (Table 4). Increased knowledge and awareness, due to education and reflection and guidance opportunities, may be part of the reason why dementia care specialists had significantly higher job strain scores. Results from analysis of factor 1 (frustrated empathy) revealed that the dementia care specialists perceived that other staff members did not care for older persons in ways that indicated that they understand dementia consequences, which may be related to education. The literature, however, contains contradictory findings about correlations between education and stress among care staff. For example, Orrung Wallin et al found that low levels of job strain among nurse assistants, who work in residential care, were associated with low education levels. ${ }^{24}$ That said, Edvardsson et al found the opposite: low education levels were associated with higher work demand. ${ }^{18}$ Two factors might explain the contradictory findings: use of different measurement tools regarding job strain/stress and varying education level classifications and descriptions. Furthermore, organizational factors, such as leadership and support, could have influenced staff-reported stress levels. ${ }^{24}$

Dementia care specialists in this study more frequently met persons with dementia and increased needs; this corresponds to factor 3: balancing competing needs. For example, dementia care specialists perceived a higher degree of job strain regarding balancing the needs of older persons against the needs of their families. Other studies show that dilemmas can arise for staff when the person with dementia and his or her family members have differing views about what is best for the person with dementia. ${ }^{36}$ The support for persons with dementia may take more time, and unexpected situations may occur. Haak contends that it is important to get to know persons with dementia and to make them feel comfortable; it takes time to maintain relationships and gain access to their experiences. ${ }^{37}$ Persons with dementia may also be exposed to risks in everyday life (e.g., falling, getting lost, and cooking accidents), ${ }^{38}$ and supervision can be a way of reducing negative outcomes from various situations. ${ }^{39}$ After a visit, home care staff must often leave the person alone because the majority of older persons with home care services in Sweden live alone. ${ }^{40}$ Leaving a person with dementia unattended might trigger job strain among staff. Dementia care specialists, who cared more extensively for persons with dementia, expressed a higher degree of job strain regarding the statement: I cannot stop thinking about older persons when I am away from work (factor 4: balancing emotional involvement). The Orrung Wallin et al's ${ }^{24}$ study reported that it is more stressful to care for persons with dementia and that nurse assistants, who worked in dementia-specific units within residential care, were associated with higher degrees of job strain than those who worked in other units.

The regression analysis revealed that not having Swedish as first language was correlated with higher job strain regarding factor 2 (difficulties understanding and interpreting). In the sample for this study, $45 \%$ of respondents indicated that they did not have Swedish as their first language. This is aligned with the studies of Orrung Wallin et $\mathrm{al}^{24}$ in Sweden ( $48 \%$ of the nursing staff were foreign born) and Chamberlain et $\mathrm{al}^{41}$ in Canada (49\% of health care aides did not have English as their first language).

Statements in Table 3 under factor 2 cover more than language. They include, for example, understanding and interpreting older persons' needs, thoughts, and behaviors. Cultural and social awareness is necessary for understanding expressions of needs and interpreting behaviors. In this study, we only asked if Swedish was the participant's first language. Perceived job strain might be related to other factors such as ethnicity and culture. Two recently published Swedish studies investigated nursing staff's and family members' experiences with older persons with dementia (of varying ethnicities) who live in residential settings. The studies reported serious misunderstandings between staff members and older persons and that staff was not able to recognize what older persons needed nor could they deliver needed care. ${ }^{42,43}$ Canadian researchers indicated that ethnicity and culture should be addressed to improve situations for care recipients and home care staff. ${ }^{44}$

The regression analyses supported the correlation between factor 5 (lack of recognition) and the CCQ total score. In line with previous research, these findings showed that higher job strain level was correlated with a more stagnated organizational climate. ${ }^{24}$ When interpreting the CCQ scores regarding reference values described by Ekvall, ${ }^{45}$ the organizational climate for this sample was stagnated. This result suggests that home care staff's perceived job strain, concerning the perception that their work is devalued, could be reduced if the organizational climate in the workplace was improved, especially in terms of how their ideas were received and reduction of interpersonal 
conflicts and emotional tensions. Thus, organizational factors are important to consider in the home care services context, for example, support from managers and supervisors, which is needed to decrease job strain among home care staff.

\section{Limitations}

Restricted sample size and convenience sample constitute the study's main limitations; consequently, the findings are more exploratory and hypothesis generating than conclusive. Despite the small sample, the two groups (dementia care specialists and other staff) were comparable regarding demographic characteristics. The analyses identified two significant differences regarding dementia care education and working evenings. These differences between the groups are reasonable, because dementia care specialists should have more dementia care education, and persons with dementia probably need $24 / 7$ assistance and more support than persons without dementia. Considering the sample size, nonparametric statistical tests are convenient. That said, parametric statistical tests were used in this study to be able to compare the findings with a previous study. ${ }^{24}$ This study used convenience sampling, which is a limitation. However, the demographic variables, such as gender, age, and length of employment for the total sample, were similar to bigger studies conducted in Sweden's home care services. ${ }^{46,47}$ Thus, caution must be taken regarding generalization of the findings, and larger multicenter studies are needed to confirm or reject the findings in this study.

The SDCS and CCQ instruments used in this study were developed and validated in Sweden; adequate validity and reliability were tested and demonstrated, for example, via selection of items, factor analysis, and test-retest reliability. ${ }^{20,24,28,48}$ In this study, reliability tests indicated acceptable Cronbach's alpha values for the SDCS total score and for four of the instrument's five factors. Factor 5 had a lower value, which indicates caution when interpreting the results. Reliability tests for the total sample indicated acceptable Cronbach's alpha values for the total CCQ score and for six of the 10 dimensions. The amount of missing data in the study was similar to previous studies. ${ }^{20,24}$ A systematic method for imputing values was used. ${ }^{32}$ And while several statistical tests were conducted, setting a $p$-value $\leq 0.05$ could be questioned. However, most of the main findings in this study were confirmed with $p$-values $<0.01$.

\section{Conclusion}

Home care staff had high mean scores on job strain in comparison with previous studies conducted in residential care. This is an important finding considering that the older population living at home is expected to increase. The study indicates that dementia care specialists and staff who did not have Swedish as their first language had higher job strain scores. Future research needs to confirm or reject these findings as many persons with dementia live at home with extensive and complex health care needs, and a great proportion of home care staff members do not have Swedish as their first language.

\section{Acknowledgments}

Karolinska Institutet's Doctoral School in Health Care Sciences and the Dementia at Home Project financed this research (Professor Lena Borell project funding from Swedish Research Council for Health, Working Life and Welfare and Strategic Research Area Health Care Science). The authors sincerely thank all home care staff members who participated in this study.

\section{Author contributions}

All authors contributed with the main part of the design, analysis, and manuscript writing. All authors read and approved the final manuscript.

\section{Disclosure}

The authors report no conflicts of interest in this work.

\section{References}

1. Christensen K, Doblhammer G, Rau R, Vaupel JW. Ageing populations: the challenges ahead. Lancet. 2009;374(9696):1196-1208.

2. Prince M, Comas-Herrera A, Knapp M, Guerchet M, Karagiannidou M. World Alzheimer report 2016: improving healthcare for persons living with dementia. London: Alzheimer's Disease International (ADI); 2016. Available from: https://www.alz.co.uk/research/WorldAlzheimerReport2016.pdf. Accessed March 30, 2018.

3. Wimo A, Jönsson L, Fratiglioni L, Sandman P, Gustavsson A, Sköldunger A. Demenssjukdomarnas samhällskostnader i Sverige 2012 [Societal costs for dementia in Sweden in 2012]. Stockholm: National Board of Health and Welfare; 2014. Available from: https://www. socialstyrelsen.se/Lists/Artikelkatalog/Attachments/19444/2014-6-3. pdf. Accessed March 30, 2018. Swedish.

4. Hewko SJ, Cooper SL, Huynh H, et al. Invisible no more: a scoping review of the health care aide workforce literature. BMC Nurs. 2015;14:38.

5. Henning C, Ahnby U, Osterstrom S. Senior housing in Sweden: a new concept for aging in place. Soc Work Public Health. 2009;24(3):235-254.

6. Ulmanen P, Szebehely M. From the state to the family or to the market? Consequences of reduced residential eldercare in Sweden. Int J Soc Welf. 2015;24(1):81-92.

7. Genet N, Boerma WG, Kringos DS, et al. Home care in Europe: a systematic literature review. BMC Health Serv Res. 2011;11:207.

8. Szebehely M, Trydegard GB. Home care for older people in Sweden: a universal model in transition. Health Soc Care Community. 2012;20(3):300-309.

9. Socialtjänstlagen [Social Services Act] SFS 2001:453. Stockholm: Socialdepartmentet. Swedish.

10. Hjalmarson I. Vem ska bestämma vad i hemtjänsten? [Who should decide what in home care services?]. Stockholm: Stiftelsen Stockholms läns Äldrecentrum (Stockholm Gerontology Research Center Foundation); 2014. Available from: http://www.aldrecentrum.se/sites/ default/files/publication/pdf/2014_2_vem_ska_bestamma_vad_i_hemtjansten_inlaga_3_mars.pdf. Accessed March 30, 2018. Swedish. 
11. Socialtjänstlagen [Social Services Act] SFS 2010:427. Stockholm: Social Department. Swedish.

12. Gens K, Hjalmarson I, Meinow B, Wånell SE. Kunskapsöversikt inom ramen för projektet hemtjänstuppdraget i Stockholm stad [Systematic review within the home care services project in Stockholm]. Stockholm: Stiftelsen Stockholms läns Äldrecentrum (Stockholm Gerontology Research Center Foundation); 2015. Available from: https://insynsverige.se/documentHandler.ashx?did=1802058. Accessed March 30, 2018. Swedish.

13. Gransjön Craftman A, Hammar LM, von Strauss E, Hillerås P, Westerbotn M. Unlicensed personnel administering medications to older persons living at home: a challenge for social and care services. Int $J$ Older People Nurs. 2015;10(3):201-210.

14. Lundgren D, Ernsth-Bravell M, Kåreholt I. Leadership and the psychosocial work environment in old age care. Int J Older People Nurs. 2016;11(1):44-54.

15. Hanson GC, Perrin NA, Moss H, Laharnar N, Glass N. Workplace violence against homecare workers and its relationship with workers health outcomes: a cross-sectional study. BMC Public Health. 2015;15:11.

16. The Swedish National Board of Health and Welfare. Nationella riktlinjer för vård och omsorg vid demenssjukdom 2010 [National guidelines for care and nursing in dementia 2010]. Stockholm: National Board of Health and Welfare; 2010. Available from: http://www.demenscentrum. se/globalassets/utbildning_pdf/nationella_riktlinjer_vard_omsorg_vid_ demens.pdf. Accessed March 30, 2018. Swedish.

17. Gens K, Wånell SE. Hemtjänst för personer med demenssjukdom [Home care for persons with dementia]. Stockholm: Stiftelsen Stockholms läns Äldrecentrum (Stockholm Gerontology Research Center Foundation); 2013. Available from: http://www.aldrecentrum.se/sites/ default/files/Global/Rapporter/2013/2013_12_hemtjänst $\% 20$ för $\% 20$ personer\%20med\%20demenssjukdom_webb.pdf. Accessed March 30, 2018. Swedish.

18. Edvardsson D, Sandman PO, Nay R, Karlsson S. Associations between the working characteristics of nursing staff and the prevalence of behavioral symptoms in persons with dementia in residential care. Int Psychogeriatr. 2008;20(4):764-776.

19. Wallin AO, Jakobsson U, Edberg AK. Job satisfaction and associated variables among nurse assistants working in residential care. Int Psychogeriatr. 2012;24(12):1904-1918.

20. Edberg AK, Anderson K, Orrung Wallin A, Bird M. The development of the strain in dementia care scale (SDCS). Int Psychogeriatr. 2015;27(12):2017-2030.

21. Knopp-Sihota JA, Niehaus L, Squires JE, Norton PG, Estabrooks CA. Factors associated with rushed and missed resident care in western Canadian nursing homes: a cross-sectional survey of health care aides. J Clin Nurs. 2015;24(19-20):2815-2825.

22. Schmidt SG, Dichter MN, Palm R, Hasselhorn HM. Distress experienced by nurses in response to the challenging behaviour of residents - evidence from German nursing homes. J Clin Nurs. 2012;21(21-22):3134-3142.

23. Knapp TR. Stress versus strain: a methodological critique. Nurs Res. 1988;37(3):181-184.

24. Orrung Wallin A, Jakobsson U, Edberg AK. Job strain and stress of conscience among nurse assistants working in residential care. $J$ Nurs Manag. 2015;23(3):368-379.

25. Gleason HP, Coyle CE. Mental and behavioral health conditions among older adults: implications for the home care workforce. Aging Ment Health. 2016;20(8):848-855.

26. Gleason HP, Boerner K, Barooah A. Supporting home health aides through a client's death: the role of supervisors and coworkers. Geriatr Nurs. 2016;37(4):278-283.

27. Ekvall G. Organizational climate for creativity and innovation. Eur $J$ Work Organ Psychol. 1996;5(1):105-123.

28. Orrung Wallin A, Edberg AK, Beck I, Jakobsson U. Psychometric properties concerning four instruments measuring job satisfaction, strain, and stress of conscience in a residential care context. Arch Gerontol Geriatr. 2013;57(2):162-171.
29. Carlfjord S, Festin K. Association between organizational climate and perceptions and use of an innovation in Swedish primary health care: a prospective study of an implementation. BMC Health Serv Res. 2015;15(1):364.

30. Söderlund M, Norberg A, Hansebo G. Validation method training: nurses' experiences and ratings of work climate. Int J Older People Nurs. 2014;9(1):79-89.

31. IBM Corp. IBM SPSS Statistics for Windows, Version 22.0. Armonk: IBM Corp; 2013.

32. Tabachnick BG, Fidell LS. Using Multivariate Statistics. 6th ed. Boston, MA: Allyn \& Bacon; 2013.

33. Edberg AK, Bird M, Richards DA, Woods R, Keeley P, Davis-Quarrell V. Strain in nursing care of persons with dementia: nurses' experience in Australia, Sweden and United Kingdom. Aging Ment Health. 2008;12(2):236-243.

34. Kim IH, Noh S, Muntaner C. Emotional demands and the risks of depression among homecare workers in the USA. Int Arch Occup Environ Health. 2013;86(6):635-644.

35. Quinn MM, Markkanen PK, Galligan CJ, et al. Occupational health of home care aides: results of the safe home care survey. Occup Environ Med. 2016;73(4):237-245.

36. Robinson L, Hutchings D, Corner L, et al. Balancing rights and risks: conflicting perspectives in the management of wandering in dementia. Health Risk Soc. 2007;9(4):389-406.

37. Haak NJ. Maintaining connections: understanding communication from the perspective of persons with dementia. Alzheimers Care Today. 2002;3(2):116-131.

38. Gilmour H, Gibson F, Campbell J. Living alone with dementia: a case study approach to understanding risk. Dementia. 2003;2(3): 403-420.

39. Horvath KJ, Hurley AC, Duffy ME, et al. Caregiver competence to prevent home injury to the care recipient with dementia. Rehabil Nurs. 2005;30(5):189-196; discussion 197.

40. The Swedish National Board of Health and Welfare. Brukarundersökning 2016: Så tycker de äldre om äldreomsorgen 2016. En rikstäckande undersökning av äldres uppfattning om kvaliteten $i$ hemtjänst och särskilt boende [User survey 2016: what the elderly think about elderly care in 2016. A nationwide survey of older persons' perception of home care quality and special housing]. Stockholm: National Board of Health and Welfare; 2016. Available from: www.socialstyrelsen. se/Lists/Artikelkatalog/Attachments/20356/2016-10-2.pdf. Accessed March 30, 2018. Swedish.

41. Chamberlain SA, Hoben M, Squires JE, Estabrooks CA. Individual and organizational predictors of health care aide job satisfaction in long term care. BMC Health Serv Res. 2016;16(1):577.

42. Söderman M, Rosendahl SP. Caring for ethnic older people living with dementia - experiences of nursing staff. $J$ Cross Cult Gerontol. 2016;31(3):311-326

43. Rosendahl SP, Söderman M, Mazaheri M. Immigrants with dementia in Swedish residential care: an exploratory study of the experiences of their family members and nursing staff. BMC Geriatr. 2016;16:18.

44. Estabrooks CA, Squires JE, Carleton HL, Cummings GG, Norton PG. Who is looking after Mom and Dad? Unregulated workers in Canadian long-term care homes. Can J Aging. 2015;34(1):47-59.

45. Ekvall G. Manual, Formulär A: Arbetsklimatet (CCQ) [Users' Guide, Survey A: Working Climate (CCQ)]. Hällefors: Hällefors Tryckeri AB; 1990. Swedish.

46. Larsson A, Karlqvist L, Westerberg M, Gard G. Perceptions of health and risk management among home care workers in Sweden. Phys Ther Rev. 2013;18(5):336-343.

47. Westerberg K, Tafvelin S. The importance of leadership style and psychosocial work environment to staff-assessed quality of care: implications for home help services. Health Soc Care Community. 2014;22(5):461-468.

48. Ekvall G. Creative Organizational Climate, Validity of the Concept and of a Measurement Tool: the Creative Climate Questionnaire CCQ. Stockholm: Organisationspsykologi; 2004. 


\section{Supplementary materials}

Table SI SDCS (total, factors, and statements) for total sample, dementia care specialists, and other staff

\begin{tabular}{|c|c|c|c|c|c|c|c|c|}
\hline \multirow[t]{2}{*}{ SDCS } & \multicolumn{3}{|l|}{ Total sample } & \multicolumn{2}{|c|}{$\begin{array}{l}\text { Dementia } \\
\text { care specialist }\end{array}$} & \multicolumn{2}{|c|}{ Other staff } & \multirow[t]{2}{*}{$p$-value } \\
\hline & $\begin{array}{l}\text { Cronbach's } \\
\text { alpha }\end{array}$ & $\mathbf{N}$ & $\begin{array}{l}\text { Mean } \\
\text { (SD) }\end{array}$ & $\mathbf{N}$ & $\begin{array}{l}\text { Mean } \\
(\text { SD) }\end{array}$ & $\mathbf{N}$ & $\begin{array}{l}\text { Mean } \\
\text { (SD) }\end{array}$ & \\
\hline Total strain & 0.92 & 57 & $5.22(1.86)$ & 29 & $5.70(2.18)$ & 28 & $4.7 I(1.32)$ & 0.04 \\
\hline Factor I: frustrated empathy & 0.85 & 64 & $5.4 I(2.38)$ & 32 & $6.15(2.63)$ & 32 & $4.67(1.86)$ & 0.01 \\
\hline $\begin{array}{l}\text { I see other staff behaving toward an older person in ways } \\
\text { that show they do not understand the effects of dementia }\end{array}$ & & 64 & $6.69(4.09)$ & 32 & $8.22(4.48)$ & 32 & $5.16(3.00)$ & $<0.01$ \\
\hline I see that an older person is suffering & & 66 & $6.6 I(3.37)$ & 33 & $7.33(3.65)$ & 33 & $5.88(2.93)$ & 0.08 \\
\hline Older persons do not receive the care I feel they are entitled to & & 64 & $7.48(3.7 I)$ & 32 & $8.19(4.08)$ & 32 & $6.78(3.22)$ & 0.13 \\
\hline I see the families of older persons suffering & & 65 & $4.97(3.08)$ & 32 & $5.47(3.35)$ & 33 & $4.48(2.75)$ & 0.20 \\
\hline I see older persons being mistreated by their families & & 64 & $3.80(2.76)$ & 32 & $4.25(2.90)$ & 32 & $3.34(2.59)$ & 0.19 \\
\hline I see other staff treating older persons badly & & 64 & $3.11(2.48)$ & 32 & $3.72(2.56)$ & 32 & $2.50(2.27)$ & 0.05 \\
\hline $\begin{array}{l}\text { Other staff tries to change what I have done for an older } \\
\text { person }\end{array}$ & & 64 & $5.23(3.37)$ & 32 & $6.00(3.84)$ & 32 & $4.47(2.66)$ & 0.07 \\
\hline Factor 2: difficulties understanding and interpreting & 0.90 & 64 & $4.43(2.13)$ & 33 & $4.76(2.30)$ & 31 & $4.07(1.91)$ & 0.20 \\
\hline $\begin{array}{l}\text { I have difficulties understanding what older persons are } \\
\text { thinking }\end{array}$ & & 66 & $5.02(2.76)$ & 33 & $5.45(3.28)$ & 33 & $4.58(2.08)$ & 0.20 \\
\hline $\begin{array}{l}\text { I have difficulties understanding what older persons are } \\
\text { trying to communicate }\end{array}$ & & 65 & $4.55(2.49)$ & 33 & $4.79(2.63)$ & 32 & $4.31(2.36)$ & 0.45 \\
\hline I have difficulties understanding older persons' needs & & 64 & $4.03(2.44)$ & 33 & $4.55(2.40)$ & 31 & $3.48(2.39)$ & 0.08 \\
\hline I find it difficult to know what is best for older persons & & 64 & $4.30(2.93)$ & 33 & $4.70(3.42)$ & 31 & $3.87(2.26)$ & 0.26 \\
\hline $\begin{array}{l}\text { I worry I might upset or hurt older persons because I do not } \\
\text { understand their needs }\end{array}$ & & 64 & $4.23(2.84)$ & 33 & $4.52(3.33)$ & 31 & $3.94(2.22)$ & 0.42 \\
\hline I cannot understand why older persons behave the way they do & & 66 & $4.27(2.30)$ & 34 & $4.44(2.00)$ & 32 & 4.09 (2.59) & 0.54 \\
\hline $\begin{array}{l}\text { I find it difficult to explain to older persons what is } \\
\text { happening in situations which may upset them (e.g., } \\
\text { showering, bathing, or toileting) }\end{array}$ & & 68 & $4.57(3.27)$ & 34 & $5.24(3.83)$ & 34 & $3.91(2.47)$ & 0.10 \\
\hline Factor 3: balancing competing needs & 0.85 & 61 & $5.95(2.97)$ & 31 & $6.85(3.46)$ & 30 & $5.02(2.01)$ & 0.01 \\
\hline $\begin{array}{l}\text { I must balance the needs of the older person against the } \\
\text { needs of his or her family }\end{array}$ & & 63 & $6.17(3.70)$ & 31 & $7.42(4.42)$ & 32 & $4.97(2.33)$ & 0.01 \\
\hline $\begin{array}{l}\text { I must balance the needs of the older person against the } \\
\text { needs of other older persons }\end{array}$ & & 61 & $5.87(4.10)$ & 31 & $7.29(4.81)$ & 30 & $4.40(2.55)$ & 0.01 \\
\hline $\begin{array}{l}\text { I must prioritize on the basis of urgency rather than fairness } \\
\text { or the needs of older persons }\end{array}$ & & 62 & $6.27(3.5 \mathrm{I})$ & 31 & $6.84(3.68)$ & 31 & $5.7 \mid(3.29)$ & 0.21 \\
\hline Older persons resist the care I want to provide & & 64 & $6.00(3.57)$ & 31 & $6.74(3.92)$ & 33 & $5.30(3.12)$ & 0.11 \\
\hline $\begin{array}{l}\text { I must balance the safety of older persons against their } \\
\text { quality of life }\end{array}$ & & 64 & $5.39(3.87)$ & 32 & $5.91(4.15)$ & 32 & $4.88(3.56)$ & 0.29 \\
\hline Factor 4: balancing emotional involvement & 0.75 & 63 & $5.18(2.5 I)$ & 30 & $5.68(2.79)$ & 33 & $4.72(2.17)$ & 0.14 \\
\hline $\begin{array}{l}\text { When an older person dies or must move, I feel as though } \\
\text { I have lost a relative or close friend }\end{array}$ & & 65 & $4.54(3.36)$ & 31 & $4.48(3.60)$ & 34 & $4.59(3.18)$ & 0.90 \\
\hline I feel that older persons are highly dependent on me & & 64 & $7.33(3.70)$ & 31 & $8.23(3.75)$ & 33 & $6.48(3.50)$ & 0.06 \\
\hline $\begin{array}{l}\text { I wish I knew more about older persons so that I could } \\
\text { understand them better }\end{array}$ & & 63 & $5.19(3.13)$ & 30 & $5.53(3.38)$ & 33 & $4.88(2.89)$ & 0.42 \\
\hline $\begin{array}{l}\text { I cannot stop thinking about older persons when I am away } \\
\text { from work }\end{array}$ & & 64 & $3.75(3.02)$ & 31 & $4.58(3.58)$ & 33 & $2.97(2.16)$ & 0.04 \\
\hline Factor 5: lack of recognition & 0.53 & 63 & $5.90(2.37)$ & 32 & $6.59(2.59)$ & 31 & $5.19(1.92)$ & 0.02 \\
\hline I feel that my work is not valued by others & & 64 & $5.59(3.86)$ & 32 & $6.88(4.16)$ & 32 & $4.31(3.11)$ & 0.01 \\
\hline $\begin{array}{l}\text { I want to do much more for older persons than my } \\
\text { employers will allow }\end{array}$ & & 66 & $7.50(4.24)$ & 34 & $8.09(4.49)$ & 32 & $6.88(3.93)$ & 0.25 \\
\hline My employers do not appreciate the work I'm doing & & 64 & $3.94(2.88)$ & 32 & $4.4 I(3.28)$ & 32 & $3.47(2.38)$ & 0.20 \\
\hline $\begin{array}{l}\text { Families of older persons do not seem to understand how } \\
\text { difficult it is to care for their relative }\end{array}$ & & 64 & $6.6 I(3.5 I)$ & 32 & 7.16 (3.89) & 32 & $6.06(3.06)$ & 0.22 \\
\hline
\end{tabular}

Notes: Possible range for SDCS I-16. High scores indicate high level of job strain. Significant values are shown in bold $(\leq 0.05)$.

Abbreviation: SDCS, Strain in Dementia Care Scale. 
Table S2 CCQ score for the total sample, dementia care specialists, and other staff

\begin{tabular}{|c|c|c|c|c|c|c|c|c|}
\hline \multirow[t]{2}{*}{ CCQ } & \multicolumn{3}{|l|}{ Total sample } & \multicolumn{2}{|c|}{$\begin{array}{l}\text { Dementia care } \\
\text { specialists }\end{array}$} & \multicolumn{2}{|c|}{ Other staff } & \multirow[t]{2}{*}{$p$-value } \\
\hline & $\begin{array}{l}\text { Cronbach's } \\
\text { alpha }\end{array}$ & $\mathbf{N}$ & Mean (SD) & $\mathbf{N}$ & Mean (SD) & $\mathbf{N}$ & Mean (SD) & \\
\hline Total CCQ & 0.93 & 61 & $1.59(0.4 \mathrm{I})$ & 28 & $1.62(0.39)$ & 33 & $1.56(0.43)$ & 0.55 \\
\hline Challenge & 0.55 & 63 & $1.92(0.61)$ & 30 & $1.94(0.5 \mathrm{I})$ & 33 & $1.90(0.70)$ & 0.80 \\
\hline Freedom & 0.69 & 62 & I.6I (0.57) & 29 & I.7I (0.49) & 33 & $1.53(0.63)$ & 0.20 \\
\hline Idea support & 0.86 & 63 & $1.60(0.63)$ & 30 & $1.63(0.62)$ & 33 & $1.57(0.64)$ & 0.69 \\
\hline Trust/openness & 0.62 & 62 & I.6I (0.55) & 29 & $1.72(0.45)$ & 33 & $1.52(0.55)$ & 0.12 \\
\hline Dynamism/liveliness & 0.68 & 62 & I.6I (0.52) & 29 & $\mathrm{I} .58(0.5 \mathrm{I})$ & 33 & $1.63(0.59)$ & 0.72 \\
\hline Playfulness/humor & 0.76 & 64 & $1.73(0.56)$ & 31 & $\mathrm{I} .75(0.54)$ & 33 & I.7I (0.58) & 0.78 \\
\hline Debate & 0.75 & 62 & $1.48(0.52)$ & 29 & $\mathrm{I} .48(0.53)$ & 33 & $\mathrm{I} .48(0.52)$ & 0.98 \\
\hline Conflicts & 0.84 & 63 & I. $10(0.72)$ & 30 & $0.99(0.79)$ & 33 & $1.20(0.66)$ & 0.25 \\
\hline Risk taking & 0.72 & 63 & $1.39(0.54)$ & 30 & $1.36(0.54)$ & 33 & I.4I (0.54) & 0.72 \\
\hline Ideas time & 0.80 & 62 & $1.03(0.60)$ & 29 & $0.97(0.60)$ & 33 & $\mathrm{I} .08(0.6 \mathrm{I})$ & 0.46 \\
\hline
\end{tabular}

Notes: Possible range for CCQ 0-3. High scores indicate a positive organizational climate, except for the conflicts dimension, where a high score indicates more stagnated organizational climate.

Abbreviation: CCQ, Creative Climate Questionnaire.

\section{Publish your work in this journal}

The Journal of Multidisciplinary Healthcare is an international, peerreviewed open-access journal that aims to represent and publish research in healthcare areas delivered by practitioners of different disciplines. This includes studies and reviews conducted by multidisciplinary teams as well as research which evaluates the results or conduct of such teams or health care processes in general. The journal covers a very wide range of areas and welcomes submissions from practitioners at all levels, from all over the world. The manuscript management system is completely online and includes a very quick and fair peer-review system. Visit http://www.dovepress.com/ testimonials.php to read real quotes from published authors. 